\title{
STUDENT USAGE OF HIGHER PRODUCTION VALUE MULTI- CAMERA LECTURE RECORDINGS IN A FIRST-YEAR ENGINEERING CHEMISTRY CLASS
}

\author{
Yasaman Delaviz and Scott D. Ramsay \\ University of Toronto \\ scott.ramsay@utoronto.ca
}

\begin{abstract}
This study explored student preference and usage patterns with multi-camera (5 cameras providing 5 unique angles) recordings of in-person lectures compared to standard single camera recordings employing a static wide shot of all chalkboards. The participants were firstyear undergraduate engineering students at the University of Toronto. Hard copy anonymous survey responses and analytical data collected from unlisted YouTube videos were used to gather feedback and data. To assess preference for multi- vs. single camera production, 6 lectures were uploaded simultaneously in both production formats. Data collected from YouTube Analytics showed a higher preference for multi-vs. single camera production, as the multi-camera versions had on average 4.1 times the number of views compared to the single-camera videos. When compared to the multi-camera productions, the single-camera videos had a $34 \%$ greater average decrease in audience retention (from the first 30 seconds to the last 30 seconds). From student survey responses, 64\% of students felt that the multi-camera recordings were more engaging compared to the single camera production. The findings of this study demonstrate that students perceive videos of high-production multi-camera as being valuable and more engaging to watch compared to the standard wide shot single camera lecture captures.
\end{abstract}

Keywords: lecture capture, undergraduate education, audience retention, multi-camera videos

\section{INTRODUCTION}

Current undergraduate students are part of Generation Z, who were born in or after 1995 [1]. This generation is considered to be the most technologically savvy population to attend University, as these individuals were born into an Internet-connected world. Generation Z has become accustomed to new technologies and multitasking while learning and studying. As a result, students of this generation face more distractions than any other generation before them. One study observed middle school, high school, and University students for 15 minutes while studying. In this observational study, the participants on average spent less than 6 minutes on the primary task (studying) before changing tasks either due to technological-driven distractions such as social media and texting, or preference for task-switching [2]. In another study, media multitasking behaviors by university students were observed during studying. On average, students engaged in $\sim 35$ distractions across the 3-hour session, with distractions lasting 6 seconds or longer [3]. Numerous studies have found that technology driven distractions negatively affect learning [4]-[6]. Therefore, the learning needs of this generation and the distractions faced while studying are different from those faced by the generations that attended University before them. As a result, educators should adapt new technologies and consider changes that better meet the needs and expectations of this generation. One strategy is to create more engaging content that may reduce the likelihood of task switching and increase watch time.

To help current undergraduate students achieve course learning objectives, many institutions have adopted blended learning approaches by integrating various flexible online learning materials such as access to recorded lectures along with the face-to-face contact time [7],[8]. Previous literature has summarized several benefits for providing lecture capture to students, which included improvement in student satisfaction in the course, enhanced student understanding in course content, and improved note-taking by the students [9], [10]. It has also been argued that students appreciate the flexibility offered with online access to lecture captures from anywhere and at any time [9]. It should also be noted that online access to lecture captures can increase accessibility to students with disabilities and non-native English speakers [10].

We have hypothesized that higher production-value multi-camera lecture capture with careful post-production editing will be more engaging to the students, which should result in greater audience retention compared to single camera productions presenting a standard static wide shot of all chalkboards. 


\section{METHOD}

The participants of this study were undergraduate engineering students enrolled in the first year Engineering Chemistry and Material Science course, at the University of Toronto. Lectures were recorded using multiple cameras positioned in locations in the classroom chosen to capture 5 unique and engaging angles. Post-production editing on the lecture captures was performed to smoothly cut between the most engaging angles throughout the lecture. The prepared videos were uploaded to YouTube as unlisted content. Links to the videos were made available to students using the Blackboard learning management system. Data was collected from YouTube Analytics to compare retention, view count, and choice of device platform used during viewing of each video. Absolute audience retention, which determines the number of views for every moment of a video as a percentage of the total views, was used to assess whether multi-camera production increases the average duration of video watched by the students. Anonymous student survey questionnaire responses were used to collect additional feedback at the end of semester. The participants degree of agreement to each question on the survey was measured by a five-level Likert scale response $(1=$ Strongly Disagree, $2=$ Disagree, $3=$ Neutral, 4=Agree, and 5=Strongly Agree). The survey collected information on users' preference for multi- vs. single-camera production, reason for watching lecture captures, and perceived usefulness. A total of 142 participants ( $81 \%$ of enrolled students in the lecture section data was collected from) completed the survey anonymously.

\section{RESULTS}

Over $91 \%$ of the anonymous survey participants agreed that having access to the recorded lectures was important (Table 1), of which $70 \%$ had strongly agreed. Seventythree percent of students reported using the lecture recordings to learn specific concepts missed in-class, while $65 \%$ of students reported using the videos for lectures missed in-person. Data collected from YouTube Analytics showed a higher preference for multi- vs. single camera production. For videos uploaded in both formats, the multicamera versions on average had 4.1 times the number of views compared to the single-camera production. The greater preference for multi-camera production was further supported by the student survey responses, with $55 \%$ of the students that were aware of both platforms reporting a preference for the multi-camera production and only $13 \%$ for the single-camera, with the remaining students indicating no preference. The multi-camera lecture recordings on average had 245 views (ranging from 108 to 541 views, with a median of 240 views), with an average view duration of $29 \%$.

Absolute audience retention was used to assess whether multi-camera production can be used to improve student engagement and duration of video watched. The singlecamera recordings had an average of $34 \%$ greater decrease in audience retention from the first 30 seconds to the last 30 seconds of the video, when compared to the multicamera productions.

Table 1: Percentage of respondents selecting either agreed or strongly agreed to the survey question.

\begin{tabular}{lc}
\hline \multicolumn{1}{c}{ Survey question } & \% \\
\hline Having access to video recorded lectures is important & 91.5 \\
The video recorded lectures made learning the course & 66.2 \\
material easier for me &
\end{tabular}

The multi-camera lecture recordings made the videos more engaging than conventional single camera recordings

I used the lecture recordings to learn specific concepts that I missed during class

I used the lecture recordings to review topics for tests and 63.4 exams

I used the lecture recordings to take comprehensive notes 44.4

I used the lecture recordings to work through concepts at 50.7 my own pace

I used the lecture recordings to review concepts that appeared more complex

I used the lecture recordings to replace lectures that I missed in-person

I have watched parts of the same video multiple times

As summarized in Table 2, students use numerous types of devices to view lectures online. The majority of lecture capture views were from computer devices, nevertheless other platforms such as mobile devices, tablets, and even televisions (TV) were used.

Table 2: Reporting the average \% of lectures viewed by each type of device, calculated from 29 multi-camera and 18 single-camera lecture captures provided to the students.

Computer Mobile Tablet TV Unknown

\begin{tabular}{cccccc}
\hline $\begin{array}{c}\text { Multi- } \\
\text { camera }\end{array}$ & 93.30 & 2.69 & 3.80 & 0.20 & 0.01 \\
$\begin{array}{c}\text { Single- } \\
\text { camera }\end{array}$ & 94.09 & 2.34 & 3.42 & 0.07 & 0.07 \\
\hline
\end{tabular}

\section{DISCUSSION}

The multi-camera production was found to be more engaging to the students, which may result in fewer nonlecture activities. Interruptions and distractions from engaging in non-lecture activities such as social media use is reported to negatively influence academic achievement [11]. Although there is no way to determine if the student were actively viewing these videos, based on the survey responses it appears that the students do find value in 
having access to these videos. The multi-camera productions on average had 4.1 times the number of views compared to the single-camera videos that were provided simultaneously. The videos were heavily used, with an average of 245 views on the multi-camera lecture captures (406 enrolled students). Students on average viewed 29\% of the multi-camera videos, which suggests that students were viewing only parts of the videos. In the survey responses, $73.2 \%$ of the students reported using the lecture recordings to learn specific concepts missed during class and $63.4 \%$ reported using the videos to review concepts that appeared to be more complex. Therefore, it is possible that students may have been fast forwarding to specific parts of the lecture.

The majority of students viewed the lecture captures using computer devices. However, a number of students used their mobile device or tablets. As such, when recording videos for online use it is important to consider the variations in screen size between the different platforms commonly used by the current generation of students.

There is value in use of multiple cameras along with post-production editing to capture the instructor and the chalkboards from different angles. In the multi-camera videos prepared for this study, cuts between camera angles were made approximately every 30 seconds to a few minutes. This was done in an attempt to make the videos more engaging. The digital generation is referred to as the 'glancing readers' as they often read selectively by browsing and scanning pages, and using keyword spotting [12]. Based on a study commissioned by Microsoft Corp., individuals on average now spend about 8 seconds on a web page before switching and looking elsewhere [1], [13], [14]. The challenge of maintaining audience retention further supports the need for improving lecture captures and the benefit of using multiple cameras. In the survey responses, students reported that the multi-camera videos were more engaging. Therefore, use of multiple cameras with frequent switching may have improved the audience retention. This observation is supported by the data collected from YouTube Analytics, with 34\% less decrease in audience retention from the first 30 seconds to the last 30 seconds of the video in the multi-camera production compared to the single camera recordings. For every lecture recording in this study, 1-3 hours of postproduction editing time was performed in addition to 1hour of videographer time for lecture recording. The current setup is time-consuming and expensive, and therefore future work will assess the use of live switching in a so-called direct-to-tape (live broadcast style) format during live recording to reduce post-production editing time while still benefitting from the advantages of the multi-camera format.

\section{CONCLUSION}

The findings of this study demonstrate that students perceive higher-production value multi-camera lecture recordings as being valuable and more engaging to watch compared to single-camera lecture captures.

\section{Acknowledgements}

Funding was provided from the office of the Dean of Applied Science and Engineering at the University of Toronto, and the Hart Teaching Innovation Professorship. The authors would like to thank the students for their feedback. This study complied with the University's policies on research ethics.

\section{References}

[1] D. C. Hampton and Y. Keys, "Generation Z students: Will they change our nursing classrooms?," J. Nurs. Educ. Pract., vol. 7, no. 4, pp. 111-115, 2017.

[2] L. D. Rosen, L. M. Carrier, and N. A. Cheever, "Facebook and texting made me do it: Media-induced task-switching while studying," Comput. Human Behav., vol. 29, no. 3, pp. 948-958, 2013.

[3] C. Calderwood, P. L. Ackerman, and E. M. Conklin, "What else do college students " do ' while studying? An investigation of multitasking," Comput. Educ., vol. 75, no. 2014, pp. 19-29, 2018.

[4] E. Wood, L. Zivcakova, P. Gentile, K. Archer, D. De Pasquale, and A. Nosko, "Examining the impact of offtask multi-tasking with technology on real-time classroom learning," Comput. Educ., vol. 58, no. 1, pp. 365-374, 2012.

[5] S. M. Ravizza, D. Z. Hambrick, and K. M. Fenn, "Nonacademic internet use in the classroom is negatively related to classroom learning regardless of intellectual ability," Comput. Educ., vol. 78, pp. 109-114, 2014.

[6] N. S. Hawi and M. Samaha, "To excel or not to excel: Strong evidence on the adverse effect of smartphone addiction on academic performance," Comput. Educ., vol. 98, pp. 81-89, 2016.

[7] A. Rahman, "A blended learning approach to teach fluid mechanics in engineering," Eur. J. Eng. Educ., vol. 42, no. 3, pp. 252-259, 2017.

[8] R. Owston, D. Lupshenyuk, and H. Wideman, "Lecture capture in large undergraduate classes: Student perceptions and academic performance," Internet High. Educ., vol. 14, no. 4, pp. 262-268, 2011.

[9] G. Preston, R. Phillips, M. Gosper, M. Mcneill, K. Woo, and D. Green, "Web-based lecture technologies: Highlighting the changing nature of teaching and learning," Australas. J. Educ. Technol., vol. 26, no. 6, pp. 717-728, 2010.

[10] S. Vajoczki, S. Watt, N. Marquis, M. Vine, and R. Liao, "Students Approach to Learning and their Use of Lecture Capture," J. Educ. Multimed. Hypermedia, vol. 20, no. 2, pp. 195-214, 2011.

[11] A. H. Zureick, J. Burk-rafel, J. A. Purkiss, and M. Hortsch, "The Interrupted Learner: How Distractions during Live and Video Lectures Influence Learning 
Outcomes," Anat Sci Educ., vol. [Epub ahea, 2017.

[12] S. Qutab, S. Iqbal, and F. S. Ullah, "Screen-Reading Habits and Use of e-Resources of Faculty of Economics and Management Sciences ' students: A study of Postgraduate Students," Libr. Philos. Pract., p. 1610, 2017.

[13] N. A. Bradbury, "Attention span during lectures: 8 seconds , 10 minutes , or more ?," Adv Physiol Educ, vol. 40, pp. 509-513, 2016.

[14] B. Shatto and K. Erwin, "Moving on From Millennials: Preparing for Generation Z," J. Contin. Educ. Nurs., vol. 47, no. 6, pp. 253-254, 2016. 